\title{
WARNER'S OPERATION FOR CATARACT
}

\author{
BY \\ R. R. JAMES \\ LONDON
}

Those who, like myself, were interested to read the letter on Sharp's knife for making the cataract section by Mr. Percy Flemming in the British Journal of Ophthalmology, Vol. Xi, page $94,192 i$, may like to see an account of how Warner performed the operation of extraction. The following account is taken from Chandler's "Treatise on the I)iseases of the Eye," 1780.

"The manner in which this operation (Warner's) may be performed is as follows : The patient being seated upon a large trunk, or box, the operator places himself exactly opposite, upon a seat of a convenient height, and in a room where the light is moderate, that the pupil may not be too much contracted.

"This being done an assistant stands behind the patient, who puts his right hand under the patient's chin, after having covered the right eye, supposing it to be the left which is to be operated upon : the assistant then places the back part of the patient's head on his breast, at the same time directing the face upwards, to prevent the sudden discharge of the vitreous humor. He afterwards lifts up the superior eyelid with two or more of his fingers, taking care not to press upon the globe of the eye above : the operator at the same time depresses the inferior eyelid, with this precaution, not to press upon the inferior part of the globe of the eve till the incision is made. The patient must look straight forwards, and a little upwards. The operator now fixes his right elbow upon his right knee; after having put his right foot firmly on the patient's seat for this purpose. He then suddenly and resolutely introduces the point of his knife through the external part of the cornea, opposite to the centre of the pupil, directing it horizontally betwixt the anterior surface of the iris, and the interior surface of the cornea, into the fore-chamber of the eye, till it penetrates through the cornea on its opposite side; when the inferior part of the cornea must be suddenly divided, by directing the blade of the knife downwards and outwards. The larger and lower the incision is made the better will the operation be likely to succeed; and if it happens that the wound thro' the cornea proves too small it must be enlarged by a pair of sharp scissars, well polished; the blade of which must be curved so that they mav have a convex and concave surface.

"The next process of the operation is to wound the aranea. This ought not to be attempted till a few minutes after the cornea has been incised: as soon as the incision is made through the 
cornea the eyelids should be set loose. By paying a proper attention to these maxims the whole of the aqueous humor will be evacuated; the iris will become flaccid and subside upon the cataract : the pupil will be dilated, and the instrument for cutting thro' the capsula may then readily be directed under the flap of the cornea to the inferior edge of the pupil. From these precautions the pupil will escape violence: to which it is very liable from the passage of the cataract through it when contracted and small. Immediately after the membrane is wounded the globe of the eve must be pressed gently upwards, that the cataract may 'be squeezed thro' the pupil and inferior part of the cornea, where the incision has been made. The cataract being thus removed the eyelids must be covered with a soft double or triple rag, dipped in a cold solution of saccharum saturni, or the pulvis cerussa comp. prepared in damask rose water, or spring water : this application must be kept on with a soft linen roller, and renewed two or three times a day. The patient must be laid on his back upon a bed or couch; and in this situation he must keep himself for some days that the wound made through the cornea may heal, and the newly secreted aqueous humor may be prevented from escaping out of the eye.

During the inflammatory state the eye should be treated with emollient fomentations and the patient's body must be kept open : opiates likewise must occasionally be administered."

Explanation of the plate.

Fig. 1. The eye with Mr. Warner's knife passing thro' the cornea.

Fig. 2. Mr. Sharp's knife in situ.

Fig. 3. The eye with the wound on the inferior part of the cornea, with the instrument passed under the cornea and lying upon the iris, for dividing the aranea.

Fig. 4. The cataract.

Fig. 5. The instrument for dividing the aranea with the point of the lancet out of its case.

Fig. 6. The curved scissars for enlarging the wound of the cornea.

The few facts which follow are taken from the "History of Guy's Hospital," by Wilks and Bettany :

Joseph Warner was born in Antigua in 1r1\%; he was educated at Westminster and apprenticed at the age of seventeen years to Samuel Sharp, surgeon to Guy's Hospital. He volunteered for active service in "the 45," and was in Scotland. A surgeon 


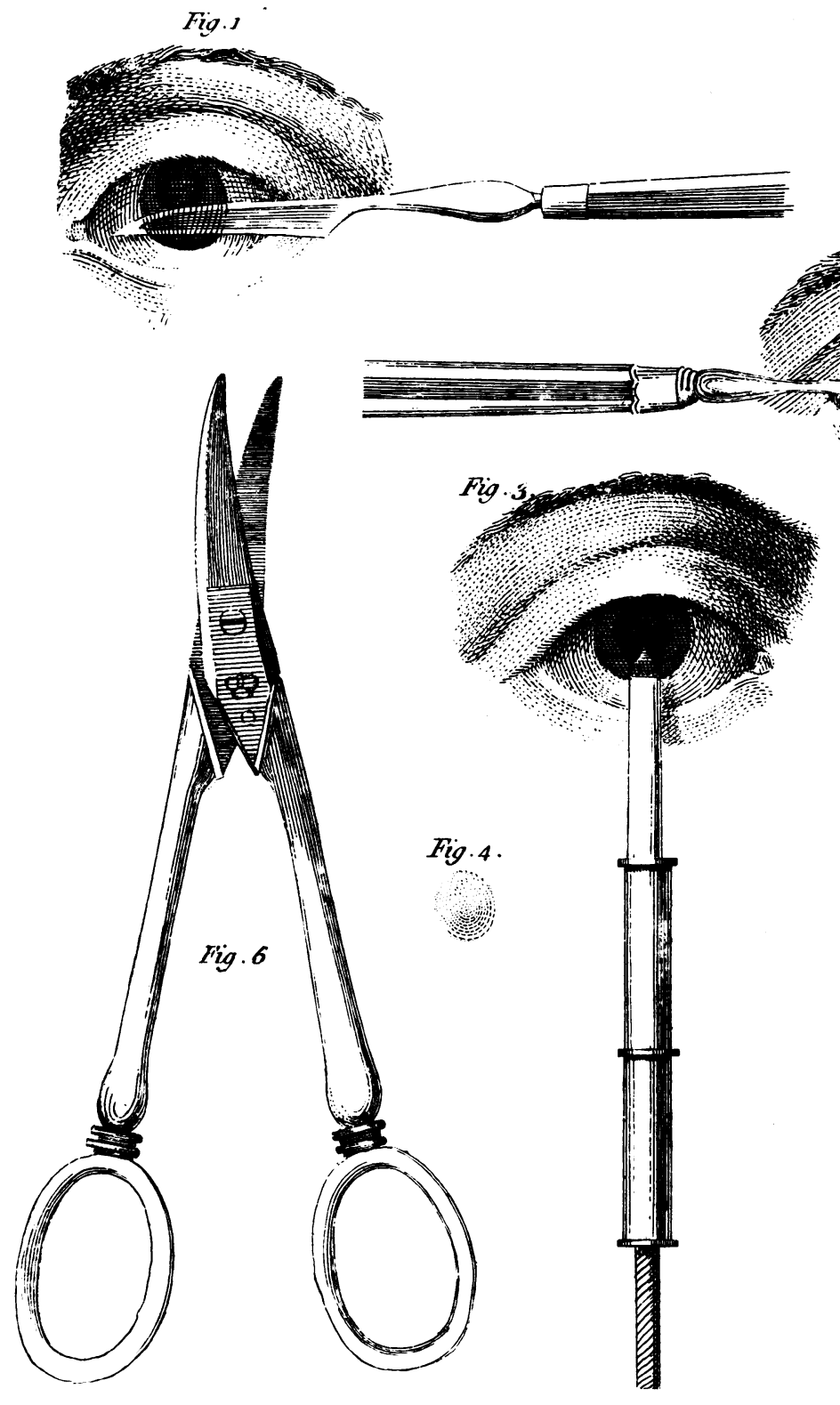

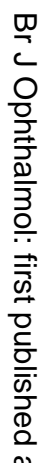

Fig. 2.

$\overrightarrow{0}$

$\stackrel{2}{\circ}$

$\vec{\omega}$

흥

$\vec{N}$

or

N

을

$=$

交

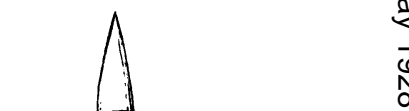

ஸ્

망

$\sum_{3}^{\circ}$

윰

\%

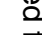

옥

כ

Fig. 5

홈

음

3

을

웅

을.

N

N

뭉

음

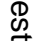

뭄

옴

तิ

뭄

8

을. 
named Cowell was also present with the forces; both Warner and Cowell were contemplating applying for the post of surgeon to St. Thomas's Hospital; while in Scotland Cowell learnt that the vacancy had been declared. Without telling Warner he obtained leave of absence on account of urgent business in London. Cowell was elected and it is said that Warner never forgave him this piece of sharp practice, and that when he met his colleagues at the Court of Assistants at Surgeons' Hall he invariably accosted them thus : "How d'ye do, gentlemen? I am glad to see you all, except Mr. Cowell" ("Wadd, Mems., Maxims, and Memoirs," $1827)$.

Warner was elected surgeon at Guy's shortly after this date. He died in 1801.

\section{ANNOTATIONS}

\section{The Work of the Medical Research Council}

The Medical Research Council has recently issued its report for the year 1926-1927.* When commenting on the previous year's Report (Brit. Jl. of Ophthal., Vol. XI, p. 346, 1927) we drew attention to Lord Balfour's account of the principles on which the Board acted in the administration of the all too scanty funds at their disposal, i.e., briefly to allow the first-class brain a free hand to carry on researches as seems best, while the second class picks out the practical plums. The sum actually provided by Parliament as a grant-in-aid was only $£ 135,000$, and had this not been largely supplemented by private donations, which included a special anonymous gift of $£ 1,500$ for the installation of a new special microscope for Mr. Barnard's use at Mill Hill, and also financial assistance given to particular pieces of work by the Miners' Welfare Fund, the Dental Board of the U.K., the Empire Marketing Board, the Distemper Research Council of the Field Newspaper, and the British Empire Cancer Campaign, much of the work could not have been carried on with success. Another factor in reducing expenditure to which Lord Balfour again draws attention is the help received from the numerous scientific men who have freely given their time and knowledge to the work of the various Committees under whose detailed supervision by far the greater part of the whole programme of work is modelled and conducted. "These thanks do not become a mere figure of speech by annual repetition. It must be a truism

${ }^{*}$ Report of the Medical Research Council for the year 1926-1927. H.M. Stationery Office, 1928. Price, 3s. 